\title{
Penerapan Penggunaan Dongkrak Ulir Elektrik Jack Sebagai Media Kompetensi Pembelajaran Sistem Hidraulik Di SMK Ma'arif NU Talang
}

\author{
Amin Nur Akhmadi ${ }^{1 *}$, M. Taufik Qurohman ${ }^{2}$, Mukhamad Khumaidi Usman ${ }^{3}$ \\ 1,2,3 Program Studi Teknik Mesin, Politeknik Harapan Bersama, Indonesia \\ Email: ${ }^{1}$ aminnurakhmadi@gmail.com, ${ }^{2}$ taufikqurohman87@gmail.com, ${ }^{3}$ khumaidioesman@gmail.com
}

\section{INFORMASI ARTIKEL}

\section{Data artikel:}

Naskah masuk, 17 September 2019

Direvisi, 12 Desember 2020

Diterima, 28 Februari 2020

\section{Kata Kunci:}

Pelatihan

Penggunaan

Sistem Hidraulik

Dongkrak Ulir

Service Toll

\begin{abstract}
ABSTRAK
Abstract - Vocational High Schools are the biggest contributor to unemployment in the area, many supporting factors such as the unstable state of the company. Basically that's not all, the teaching process at the Vocational School is at the forefront of increasing unemployment rates for SMK graduates. From the results of community service activities the following conclusions with the existence of community service activities at SMK Ma'arif Nu Talaang, Tegal Regency, it provides knowledge, understanding and innovation of efficient power transfer system equipment in accordance with Operational Procedures for Safety Procedures. Speed up the work when practicing lifting a car to change tires in the subjects of the power transfer system competency with the SOP equipment so as to make students competent in their performance practices
\end{abstract}

\begin{abstract}
Abstrak- Sekolah Menengah Kejuruan adalah penyumbang terbesar angka pengangguran pada daerah tersebut, banyak beberapa faktor pendukung seperti halnya keadaan perusahaan yang tidak stabil. Pada dasarnya tidak itu saja, proses pengajaran pada SMK tersebut menjadi terdepan dalam peningkatan angka pengangguran tingkat lulusan SMK. Dari hasil kegiatan pengabdian kepada masyarakat diperoleh kesimpulan dengan adanya kegiatan pengabdian masyarakat di SMK Ma'arif Nu Talaang Kabupaten Tegal maka memberikan pengetahuan, pemahaman dan inovasi terhadap peralatan system pemindah daya yang efisien sesuai Standar Operasional Prosedur Keselamatan. Mempercepat pekerjaan pada saat praktek mengangkat mobil untuk mengganti ban dalam mata pelajaran kompetensi system pemindah daya dengan peralatan yang SOP tersebut sehingga membuat siswa kompeten dalam praktek kinerjanya
\end{abstract}

\section{Korespondensi:}

\section{Amin Nur Akhmadi}

Program Studi Teknik Mesin, Politeknik Harapan Bersama

J1. Mataram No. 09, Pesurungan Lor, Kota Tegal, Indonesia 


\section{PENDAHULUAN}

Lulusan sekolah menengah kejuruan penyumbang terbesar angka pengangguran pada daerah tersebut, banyak beberapa faktor pendukung seperti halnya keadaan perusahaan yang tidak stabil karena naik mahalnya biaya operasional akibat naik turun mata uang Dollar Amerika. SMK Ma'arif NU Talang Kecamatan Talang sekolah ini terletak di Desa Talang Kabupaten Tegal dimana jumlah Siswasiswinya mencapai 765 jiwa, dan kebanyakan masyarakatnya berprofesi sebagai wirausaha, seperti halnya UKM. Selain itu juga angka penganguran bagi lulusan sekolah menengah kejuruan adalah minimnya keterampilan yang dikuasai setelah tamat belajar. Pada dasarnya tidak itu saja, proses pengajaran pada SMK tersebut menjadi terdepan dalam peningkatan angka pengangguran tingkat lulusan SMK (Ratnata, 2012).

Pada persaingan dunia pendidikan banyak bermunculan sekolah-sekolah baru dengan tingkat kesiapan yang minim, sehingga proses pembalajaran tidak bisa berjalan dengan maksimal tidak sesuai dengan prosedur yang tertuang pada pendirian sekolah tersebut.

Tujuan pengabdian ini adalah memberikan bekal ketrampilan/kompetensi system hidraulik, sekolah SMK Ma'arif NU Talang sebagai media perubahan kearah positif bagi siswa - siswi Alat-alat yang memadai, ruang kelas dan praktikum memberikan masukan kepada siswa untuk lebih maju dalam kompetensi belajar. Ma'arif NU Talang yang kekurangan dan fasilitas praktikum yang representatif dan metode pembelajaran yang tepat adalah kunci utama meningkatkan kualitas lulusan dan ketrampilan lulusan yang diperoleh sehingga kemandirian masing-masing lulusan dapat dijadikan acuan untuk melamar pekerjaan.

Penurunan kualitas dan level kompetensi akibat bisnis dunia pendidikan yang berkembang pesat sekarang ini sehingga perlunya diadakan pengabdian masyarakat analisa pengaruh variasi timer controller terhadap waktu pemanasan ban dalam motor pada alat tambal ban elektrik sehingga diharapkan dapat menambah keterampilan agar bisa digunakan pada saat mencari pekerjaan. Materi praktik diarahkan pada proses penggunaan dongkrak ulir elektrik (SuudiAhmad, 2013), Tanggapan dari guru dan siswa SMK Ma'arif NU Talang dengan kompetensi pelatihan ini dapat memberikan tambahan ilmu tentang sistem hidraulik (Ridho, 2004) karena siswa dapat menggunakan alat - alat praktek peraga.

\section{METODE PELAKSANAAN}

Tahapan-tahapan kegiatan yang yang dilakukan pada kegiatan pengabdian ini adalah dilakuakn dengan menggunakan beberapa tahap, yaitu mulai dari tahapan perencanaan, peaksanaan dan akhir pelaksanaan. Tahapan perencanaan dilakukan dengan dilakukannya terlebih dahulu pemetaan dan penilaian terhadap mitra kegiatan, disini yang menjadi mitra adalah SMK Ma'arif NU Talang.

Pada tahapan pelaksanaan kegiatan dilakukan dengan mennggunakan metode learning by doing, artinya kegiatan dilakuakn dengan memberikan berupa pelatihan. Pada pelaksanaanya tim memberikan arahan dan contoh, kemudian peserta kegiatan melakukan praktek apa yang dicontohkan. Tahapan akhir dilakukan dengan melakukan evaluasi kegiatan. Evaluasi ini dilakukan sebagai langkah-langkah dalam menili keefektifan pelatihan yng dilaksanakan, salah satunya adalah dengan memebrikan questioner kepada peserta pelatihan untuk menilai tingkat keberhasilan kegiatan yang dilaksanakan.

Berdasarkan pelatihan penerapan penggunaan dongkrak ulir yang diperoleh hasil berdasarkan pengamatan langsung di SMK Ma'arif NU Talang Kabupaten Tegal telah dilaksanakan penerapan penggunaan dongkrak ulir elektrik jack sebagai media kompetensi pembelajaran sistem hidraulik (Akhwan et al., 2020; Akmone \& Suwardi, 2017; Sularso, 2000) di SMK Ma'arif $\mathrm{Nu}$ Talang kepada siswa di SMK tersebut. Tujuan yang ingin dicapai dari kegiatan pengabdian masyarakat ini adalah sebagai berikut:

a) Siswa mampu mengenali bagian-bagian dongkrak seperti, motor listrik, ulir kotak, pengungkit model jembatan, kabel dan saklar serta penjepit untuk baterai.

b) Siswa mahir menggunakan dongkrak ulir elektrik guna mempercepat dan membantu dalam pekerjaan mengganti ban pada mobil

c) Siswa mampu menggunakan dongkrak dengan baik sehingga dapat menjadi usaha untuk mempersiapkan tenaga ahli yang berkualitas menyesuaikan menurut 
kebutuhan di era teknologi rekayasa otomotif

\section{HASIL DAN PEMBAHASAN}

Kegiatan pengabdian Masyarakat Penggunaan dongkrak ulir elektrik jack dapat berjalan lancar, pelatihan penggunaan alat bantu perbengkelan pada mata pelajaran kompetensi sistem hidraulik sangat mengacu bagi siswa jurusan otomotif. Kebanyakan siswa jurusan otomotif mengeluhkan kurangya pembelajaran tentang sistem pemindah daya yang menggunakan system hidraulik elektrik dengan peralatan yang masih sederhana.

Siswa jurusan otomotif menyadari sepenuhnya bahwa peralatan perbengkelan yang mereka gunakan masih kurang dari standar SOP yang sesuai dan memberin keselamatan untuk pemakaianya. Pihak Sekolah dan Jurusan bertanggung tanggung jawab atas kegiatan penggunaan dongkrak ulir elektrik di SMK yang dilaksanakanya, sehingga pihak guru otomotif harus bisa membimbing para siswa terutama jurusan otomotif pada saat praktek, untuk itu diperlukan pelatihan tambahan yang meningkatkan kualitas praktek syistem hidraulik dengan menerapkan model pelatihan penggunaan dongkrak ulir elektrik pada saat praktek system pemindah daya untuk mengangkat mobil. Hasil pelatihan akan banyak bermanfaat bagi siswa dalam bentuk pelatihan secara langsung kepada siswa jurusan otomotif, oleh karena itu siswa dapat memperoleh ilmu guna meningkatkan kompetensi kemampuan kompetensi sistem pemindah daya pada dongkrak.

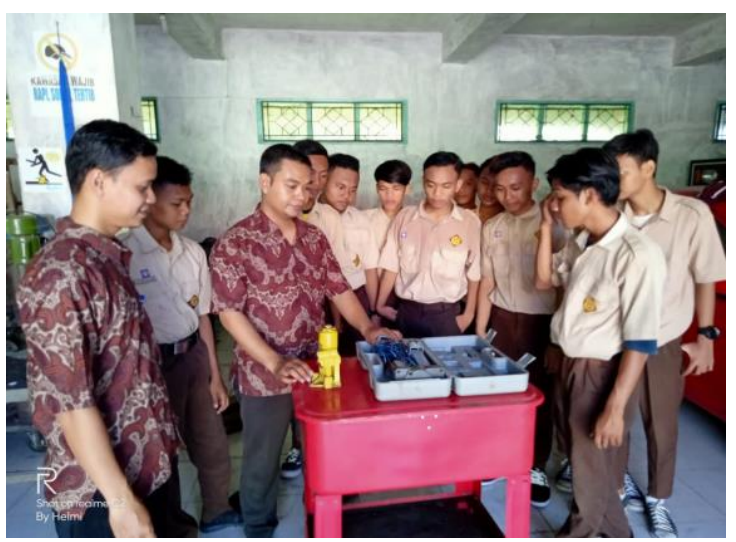

Gambar 1. Kegiatan Pengabdian di SMK Ma'arif $\mathrm{Nu}$ Talang

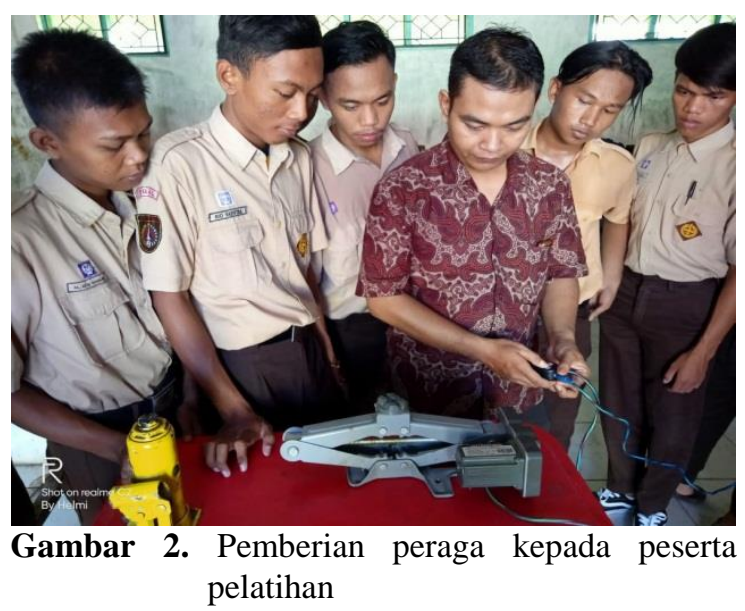

Pada Gambar 1 dan Gambar 2 memperlihatkan proses kegiatan penggunaan dongkrak ulir elektrik yang diikuti oleh para peserta kegiatan. Pada kegiatan ini proses kegiatan pembelajaran yang dilakukan oleh tim pelaksana PKM, dimana pada proses tersebut terdapat dosen dan peserta didik serta tim dari mahasiswa politeknik harapan bersama.

Dalam pelaksanaan kegiatan pelatihan penggunaan dongkrak ulir elektrik tersebut untuk memperoleh hasil luaran yang optimal maka dilakukan pendampingan baik itu pada saat proses pelaksanaan maupun pasca pelaksanaan pelatihan praktek. Pada pelatihan ini Mahasiswa dilibatkan sebagai tim pendamping yang mendampingi peserta pelatihan agar setiap peserta dapat dengan mudah baik dalam proses praktek menggunakan dongkrak pada mobil tersebut.

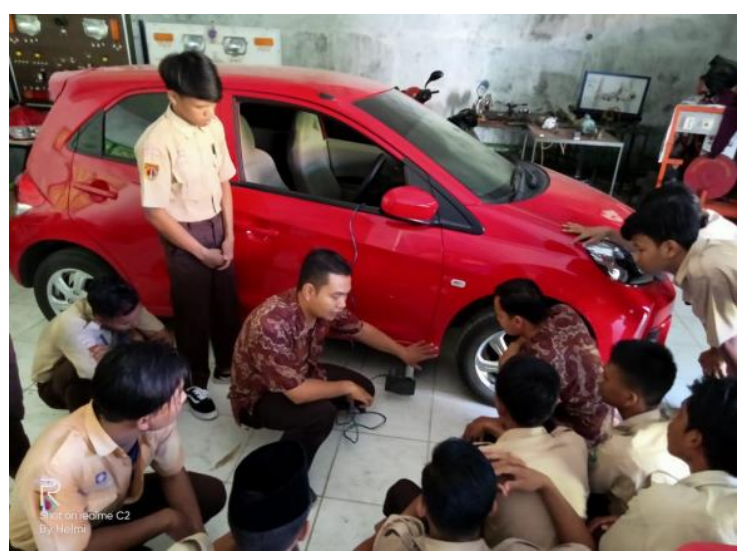

Gambar 3. Proses Pendampingan peserta kegiatan

Pada Gambar 3 memperlihatkan kegiatan pendampingan pada saat proses praktek, dimana pendampingan dilakukan oleh tim pelaksanaan PKM dan Mahasiswa. Pada proses 
pendampingan ini peserta kegiatan diarahkan dan dibimbing langsung face-to face sehingga harapannya dapat lebih optimal dalam proses

Kegiatan pengabdian pada masyarakat ini menghasilkan beberapa kegiatan yang dihasilkan diantaranya adalah pemberian materi pelatihan yang diberikan kepada para siswa SMK Ma'arif $\mathrm{Nu}$ Talang diterima dengan respon yang positif oleh para peserta kegiatan, disamping itu penggunaan media praktek dongkrak ulir elektrik yang dianggap untuk tambahan praktek kompentensi system hidraulik oleh para peserta memberikan daya tarik tertentu bagi siswa sehingga banyak para peserta pelatihan yang tertarik.

Berdasarkan hasil praktek terhadap penggunaan dongkrak ulir elektrik ini, telah dihasilkan beberapa konsep dalam dongkrak (SuudiAhmad, 2013) dari Kompetensi mata pelajaran tentang dongkrak sehingga setelah kegiatan ini selesai para peserta kegiatan dapat langsung mempraktekannya. Adanya ketertarikan dan keinginan dari kepala Sekolah SMK Ma'arif $\mathrm{Nu}$ Talang Kabupaten tegal untuk dapat mengimplementasikan hasil dari program pelatihan yang telah dilaksanakan.

\section{KESIMPULAN}

Berdasarkan hasil pelaksanaan kegiatan dari pelaksanaan PKM oleh tim dosen dan mahasiswa yang diselenggarakan di SMK Ma'arif NU Talang, diperoleh beberapa kesimpulan dan saran perbaikan untuk kegiatan selanjutnya.

Dari hasil kegiatan pengabdian kepada masyarakat penerapan penggunaan dongkrak ulir elektrik jack dapat disimpulkan bahwa dengan adanya pengabdian masyarakat di SMK Ma'arif NU Talang Kabupaten tegal maka memberikan pengetahuan, pemahamampemahaman dan inovasi terhadap peralatan system pemindah daya yang efisien sesuai standar operasional prosedur keselamatan, dan mempercepat pekerjaan pada saat praktek mengangkat mobil untuk mengganti ban dalam mata pelajaran kompetensi system pemindah daya dengan peralatan yang SOP tersebut sehingga membuat siswa kompeten dalam praktek kinerjanya.

\section{UCAPAN TERIMA KASIH}

Terimakasih kepada semua pihak yang sudah mendukung dan berpartisipasi pada pelaksanaan kegiatan PKM ini, khususnya kepada civitas akademika SMK Ma'arif NU Talang

\section{DAFTAR PUSTAKA}

Akhwan, S., Djaelani, A. R., \& Setiawan, T. (2020). Peningkatkan Hasil Belajar Memahami Dasar-Dasar Sistem Hidrolik Melalui Model Pembelajaran Inquiry Dengan Bantuan Alat Peraga. Journal of Vocational Education and Automotive Technology, 1(2), 41-48.

Akmone, L. D., \& Suwardi, H. (2017). Meningkatkan Hasil Belajar Kompetensi Dasar Hidrolik Dengan Menggunakan Model Pembelajaran Snowball Throwing Siswa Kelas X Teknik Kendaraan Ringan SMK N 2 Kupang Tahun Ajaran 20142015. Komodo Jurnal Pendidikan Teknik Mesin, 1(2), 112-118.

Ratnata, I. W. (2012). Konsep Pemikiran dalam Pengembangan Pendidikan Vokasi untuk Menghadapi Tuntutan Dunia Kerja. Prosiding APTEKINDO.

Ridho, M. (2004). Pemeliharaan Sistem Hidrolik. Depdiknas.

Sularso, H. T. (2000). Pompa dan kompresor: pemilihan, pemakaian dan pemeliharaan. PT Pradnya Paramitha.

SuudiAhmad. (2013). Perencanaan Gearboxdan Perhitungan Daya Motor pada Modifikasi Dongkrak Ulir Mekanis Menjadi Dongkrak Ulir Elektrik. Mechanical, 4(2), 38-43. 